\title{
SCIENTIFIC REPORTS

\section{OPEN A facile non-solvent induced phase separation process for preparation of highly porous polybenzimidazole separator for lithium metal battery application}

\author{
Jiaying Wang ${ }^{1}$, Yang He${ }^{1}$, Quan Wu ${ }^{1}$, Yunfeng Zhang ${ }^{1 *}$, Zhiyuan $\mathrm{Li}^{3}$, Zhihong Liu ${ }^{2}$, \\ Shikang Huo ${ }^{1}$, Jiaming Dong ${ }^{1}$, Danli Zeng ${ }^{1}$ \& Hansong Cheng ${ }^{1}$
}

The drawbacks of low porosity, inferior electrolyte wettability, low thermal dimensional stability and permissive lithium dendrite growth of the conventional microporous polyolefin-based separators hinder their widely application in the high power density and safe Lithium ion batteries. Herein, highly porous polybenzimidazole-based separator is prepared by a facile non-solvent induced phase separation process (NIPS) using water, ethanol, chloroform and ethyl acetate as the coagulation bath solvent, respectively. It was found that the ethanol is suitable to fabricate uniform morphology macroporous separator with the porosity of $92 \%$, electrolyte uptake of $594 \mathrm{wt} . \%$, and strong mechanical strength of 15.9 MPa. In addition, the experimental tests (electrochemical analysis and XPS test) and density functional theory calculation suggest that the electron-rich imidazole ring of polybenzimidazle can enhance $\mathrm{Li}^{+}$mobility electrostatic attraction interaction while the block the $\mathrm{PF}_{6}{ }^{-}$mobility via electrostatic repulsion interaction. Therefore, high $\mathrm{Li}^{+}$transference number of 0.76 was obtained for the neat polybenzimidazole-based polymer electrolyte. As a proof of concept, the $\mathrm{Li} / \mathrm{LiFePO}_{4}$ cell with the polybenzimidazole-based polymer electrolyte/1.0 $\mathrm{M} \mathrm{LiPF}_{6}{ }^{-}$ethylene carbonate/dimethyl carbonate ( $v: v=1: 1)$ electrolyte exhibits excellent rate capability of $>100 \mathrm{mAh} \mathrm{g}^{-1}$ at $6 \mathrm{C}\left(1 \mathrm{C}=170 \mathrm{~mA} \mathrm{~g}^{-1}\right)$ and superior cycle stability of 1000 cycles.

Anode materials with higher specific capacity than the commercialized graphite are currently one of the most challenges for the next-generation battery system ${ }^{1}$. Among them, Li metal anode has attracted much attention in the past decade due to its highest specific capacity $\left(3860 \mathrm{mAh} \mathrm{g}^{-1}\right)$ and the lowest potential $(-3.04 \mathrm{~V} \mathrm{vs} \text {. NHE })^{2}$. However, the uncontrolled dendritic and mossy lithium growth leads to short cycle life, low coulombic efficiency and even serious safety issues by the internal short circuit ${ }^{3}$. Numerous efforts have been devoted to increasing $\mathrm{Li}^{+}$ transference number of electrolyte for uniform deposition of lithium to suppress its dendrite growth ${ }^{4-6}$. Recently, single ion conducting polymer electrolytes with $\mathrm{Li}^{+}$transference number close to 1.0 have been proved as an effective strategy ${ }^{7-12}$. Unfortunately, the high cost of both materials and film-forming process largely hinder their commercialization. Another approach to increase $\mathrm{Li}^{+}$transference number is to add a promoter and enhance the $\mathrm{Li}^{+}$dissociation, such as metal oxides ${ }^{13}$, ceramics ${ }^{14,15}$ or $\mathrm{MOFs}^{16}$. However, the precipitation of promoters from the membrane will lead to irreversible performance loss ${ }^{17,18}$.

The high thermal dimensional stability and fire retardancy of separators are of great importance to mitigate fire hazards by avoiding the short circuit ${ }^{19,20}$. The commercial microporous polyolefin separators, i.e., polyethylene (PE) and polypropylene (PP), suffer from severe thermal dimensional shrinkage at elevated temperatures $\left(100-150^{\circ} \mathrm{C}\right)^{21}$. In addition, the low porosity $(30-40 \%)$ largely limits the electrolyte uptake, leading to low ionic

${ }^{1}$ Sustainable Energy Laboratory, Faculty of Material Science and Chemistry, China University of Geosciences (Wuhan), 388 Lumo RD, Wuhan, 430074, China. ${ }^{2}$ School of Environment and Civil Engineering, Dongguan University of Technology, No.1, Daxue Road, Songshan Lake, Dongguan, Guangdong Province, 523808, P. R. China. ${ }^{3}$ National Quality Supervision \& Inspection Center of Lithium Battery Products (Shandong), Intelligent Manufacturing Town, Fuyuan 3rd Road, National High-tech Zone, Zaozhuang, Shandong, 277800, P. R. China. *email: zhangyf329@gmail.com 
(a) Chemical structure of PBI

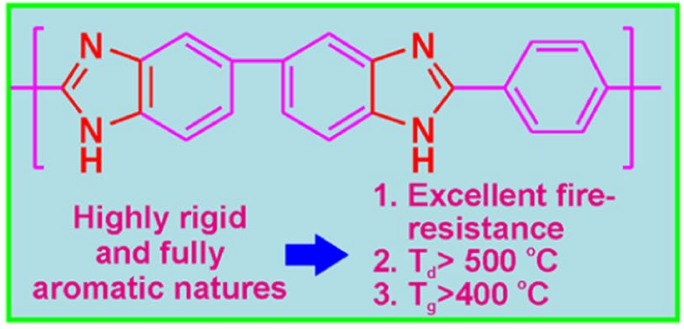

\section{(b) Cojugated interaction}

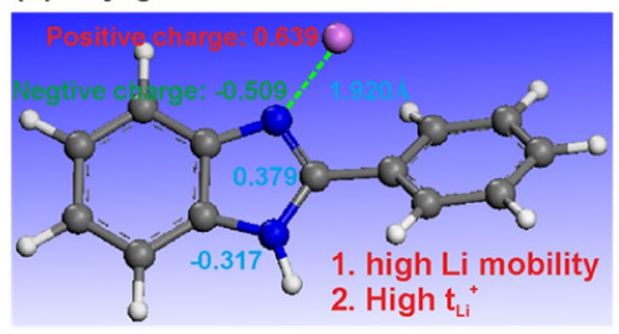

(c) NIPS process for the sponge-like architecture

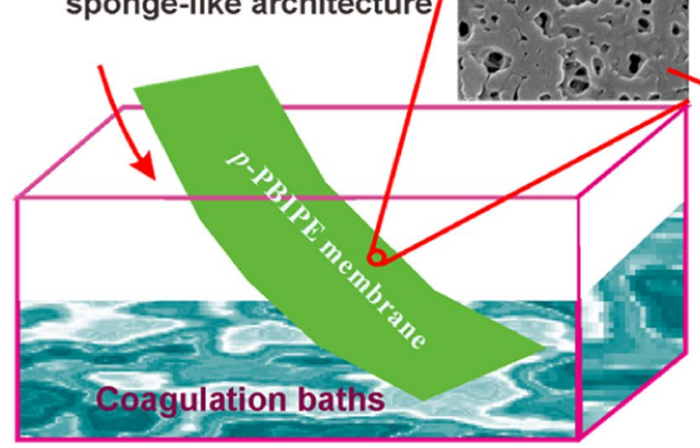

(d) p-PBIPE membrane for LIB

high cyclability (1000 cycles at 6 C)

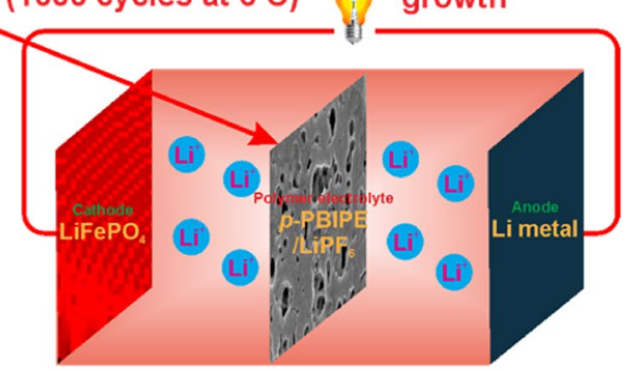

Figure 1. (a) Schematic illustration of the composition and advances of PBI, (b) conjugated interaction the PBI and $\mathrm{Li}^{+}$, (c) fabrication of $p$-PPBIPE membrane, and (d) $\mathrm{Li} / \mathrm{LiFePO}{ }_{4}$ cell with $p$-PPBIPE membrane.

conductivity $22-24$. Moreover, the polyolefin based separators have poor compatibility with the electrolyte due to its hydrophobicity, which hampered fast absorption of large amount of electrolytes for effective ionic mobility ${ }^{25}$.

As one of the most popular engineering plastics, the fully aromatic polybenzimidazole (PBI) has intrinsically high thermal stability (thermal decomposition, $\mathrm{T}_{\mathrm{d}}>550^{\circ} \mathrm{C}$ ). Li et al. fabricated the porous PBI-based separator via water vapor induced phase immersion method, the as-prepared membrane possesses the porosity of $81 \%$, and electrolyte uptake of $328 \%{ }^{26}$. Liang and his co-workers performed a blending phase inversion to prepare the micropores of PBI-based membrane via extracting poly(ethylene glycol)-10000 (PEG-10000) from the dry OPBI/PEG blend membranes with water ${ }^{27}$. The high porosity of $70 \%$ and electrolyte uptake of $316 \%$ were achieved when the PEG-10000 content was up to $150 \mathrm{wt} . \%$. However, the mechanical property was largely sacrificed and the mechanical strength was decreased to $10 \mathrm{MPa}$, which is about two-thirds of commercial Celgard 2400 separator.

The lithium ion transference number $\left(t_{L i}^{+}\right)$is one of the most critical parameters of the electrolyte for application in lithium metal batteries by suppressing lithium dendrite growth. The relationship between the $t_{L i}^{+}$and lithium dendrite growth can be illustrated by using the Equation: $\tau=\pi \mathrm{D}\left(\frac{e C_{0}}{22 t_{-}}\right)$, where $\tau$ is time consume to achieve complete ion depletion, $D$ is the ambipolar diffusion coefficient, $e$ is the electric charge, $C_{0}$ is the initial concentration, $J$ is the current density and $t_{-}$is the transference number of anions. It indicates that reduce the $t_{-}$or increase transference of $t_{L i}^{+}$can increase the deplete time of $\mathrm{Li}^{+}$and suppress lithium dendrite growth.

In the present, a facile non-solvent induced phase separation process was performed to fabricate highly porous PBI-based membranes by using four different non-solvent, water, ethanol, chloroform and ethyl acetate as the coagulation bath solvent, respectively (Fig. 1b). The results indicate that ethanol induced phase separated porous membrane possesses highest porosity of $92 \%$ and electrolyte uptake of 594\%, which are almost 3 times and 7 times higher than those of commercial PP separator, respectively. In addition, the porous membrane displays a strong mechanical strength of $15.8 \mathrm{MPa}$, which is even higher than the value of $14.5 \mathrm{MPa}$ for commercial PP separator. It is beneficial for both incorporation of more electrolytes and uniform Li stripping/plating ${ }^{28,29}$. In addition, the strong electron-rich feature of imidazole ring favors $\mathrm{Li}^{+}$dissociation from lithium salt by the strong conjugated interaction (Fig. 1c), enhances $\mathrm{Li}^{+}$diffusion and hence its transference number. The $\mathrm{Li}^{+}$transference number of PBI-based polymer electrolytes without any additives is as high as $0.76^{30}$. After impregnation of $1.0 \mathrm{M}$ $\mathrm{LiPF}_{6}{ }^{-} \mathrm{EC} / \mathrm{DMC}(\mathrm{v}: \mathrm{v}=1: 1)$ into the $p$-PBIPE membrane, the $\mathrm{Li} / \mathrm{LiFePO}_{4}$ cell (Fig. 1d) exhibits excellent rate capability and superior cycle stability for over 1000 cycles at $6 \mathrm{C}$. These make the PBI-based polymer electrolyte for advanced Li metal batteries with high safety and performance.

\section{Results and Discussion}

Membrane morphology. To prepare a polymer electrolyte membrane with high porosity and appropriate mechanical strength, four solvents (water, ethanol, ethyl acetate and chloroform) are selected as the coagulation bath for the NIPS process, where the as-prepared membranes are denoted as $w p$-PBIPE, $e p$-PBIPE, ap-PBIPE, 

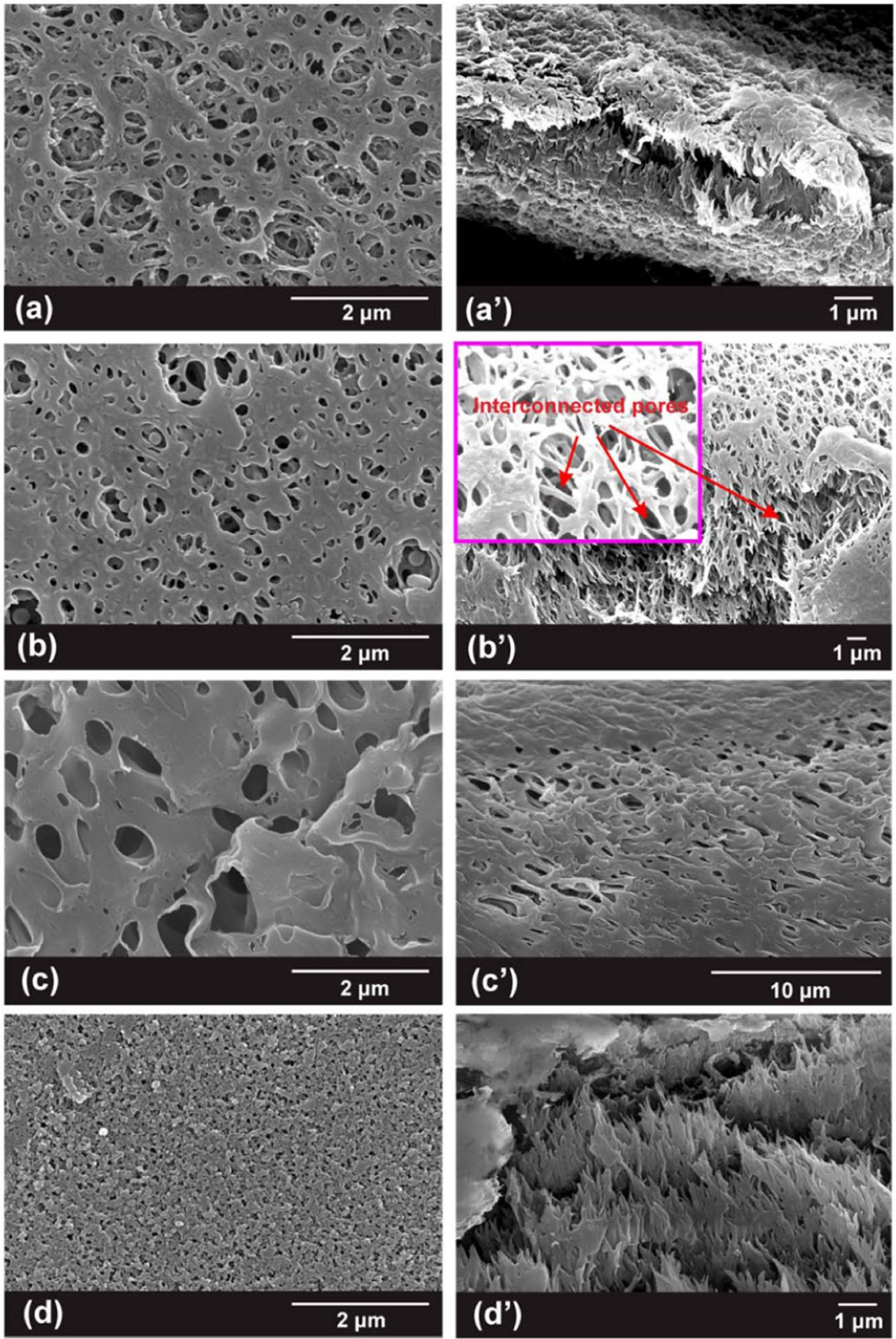

Figure 2. SEM images of as-prepared $p$-PBIPE membranes. Surfaces: (a) $w p$-PBIPE, (b) $e p$-PBIPE, (c) $a p$ PBIPE, and (d) $c p$-PBIPE; cross-section: (a') $w p$-PBIPE, (b') ep-PBIPE, (c') $a p$-PBIPE, and (d') $c p$-PBIPE.

and $c p$-PBIPE, respectively. Scanning electron microscopy (SEM) images of the four membranes are shown in Fig. 2, and the key parameters, such as porosity, electrolyte uptake and mechanical strength, are listed in Table 1. The $w p$-PBIPE (Fig. 2a and a') and ep-PBIPE (Fig. 2b and b') membranes display more favorable pore architectures than that of the $a p$-PBIPE (Fig. $2 c$ and c') and $c p$-PBIPE (Fig. $2 \mathrm{~d}$ and d') membranes. Simultaneously, the $w p$-PBIPE and $e p$-PBIPE show much higher porosities and more electrolyte uptake than those of the ap-PBIPE and $c p$-PBIPE (Table 1). The ap-PBIPE exhibits the highest mechanical strength of $23.5 \mathrm{MPa}$, while the high toxicity as well as high cost of the ethyl acetate hinders its large-scale application. In addition, the non-uniform pore architecture gives rise to detrimental effect on the battery performances ${ }^{31}$. In particular, the ep-PBIPE exhibits high porosity and appropriate mechanical strength of $15.9 \mathrm{MPa}$, higher than mechanical strength of $14.5 \mathrm{MPa}$ in the transverse direction for the commercial Celgard separator ${ }^{32,33}$, which is greatly beneficial for improving battery cycle stability ${ }^{34,35}$. Furthermore, the ep-PBIPE displays uniform and interconnected pore structure, indicating the smooth $\mathrm{Li}^{+}$diffusion, which is similar to the commercial Celgard separator (Fig. S1). Besides, the low cost and low toxicity of the ethanol coagulation bath makes the ep-PBIPE promising for large-scale application. 


\begin{tabular}{|l|l|l|l|l|c|}
\hline Properties & $\begin{array}{l}\text { Thickness } \\
(\boldsymbol{\mu} \mathbf{m})\end{array}$ & Porosity $(\%)$ & $\begin{array}{l}\text { Electrolyte } \\
\text { uptake }(\%)\end{array}$ & $\begin{array}{l}\text { Mechanical } \\
\text { strength }(\mathbf{M P a})\end{array}$ & $\begin{array}{l}\text { Elongation } \\
(\%)\end{array}$ \\
\hline$w p$-PBIPE & 29 & 87 & 614 & 2.3 & 4.5 \\
\hline$e p$-PBIPE & 33 & 92 & 594 & 15.9 & 7.6 \\
\hline$a p$-PBIPE & 31 & 85 & 521 & 23.5 & 13.0 \\
\hline$c p$-PBIPE & 34 & 82 & 507 & 8.4 & 3.1 \\
\hline Celgard separator & 23 & 31 & 80 & 14.5 & 824.9 \\
\hline
\end{tabular}

Table 1. Tabulated properties of the porosity, electrolyte uptake, and mechanical strength of the as-prepared $p$ PBIPE membranes.
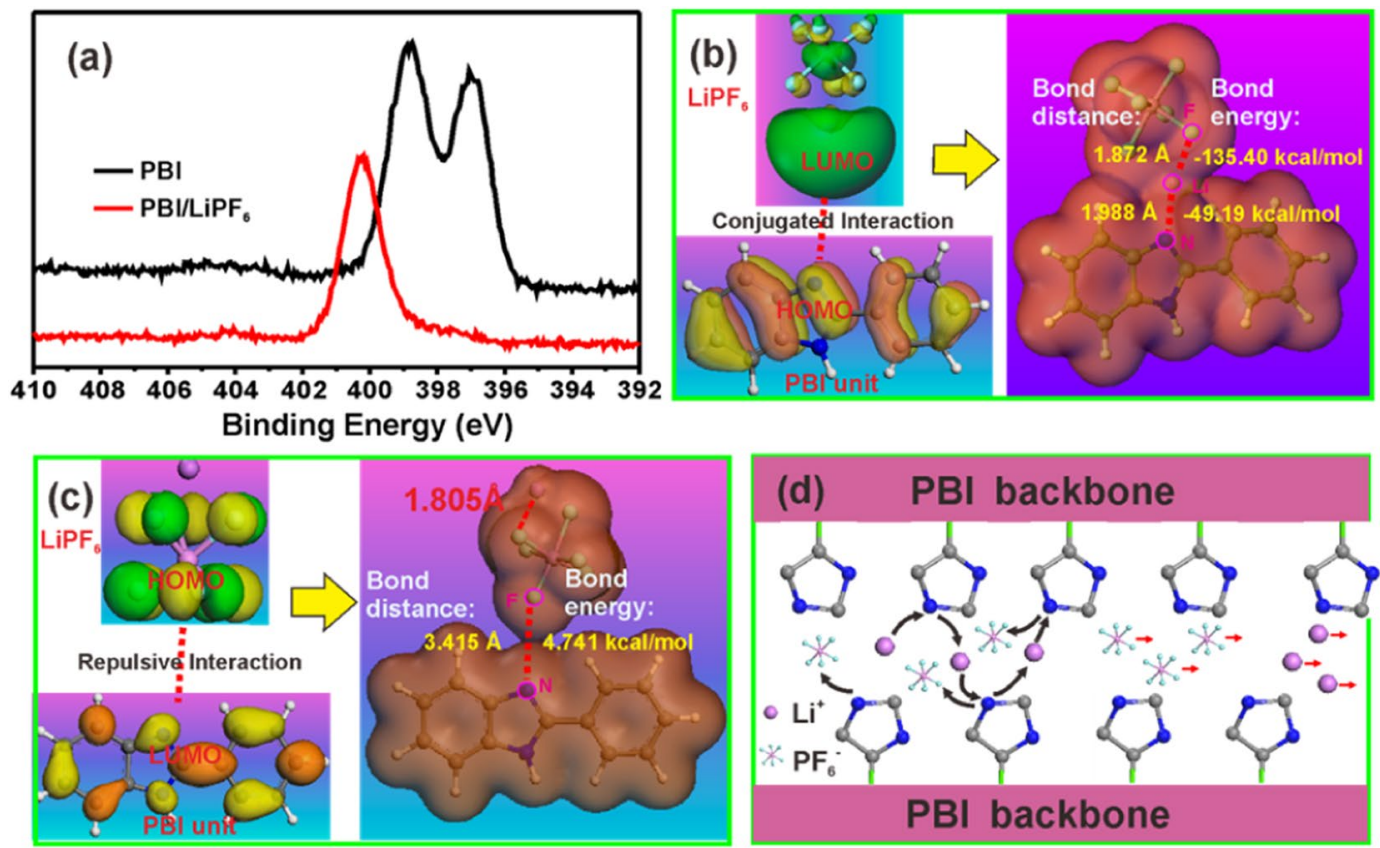

Figure 3. (a) XPS spectra of N1s of the neat PBI membrane and the PBI immersed in $1.0 \mathrm{M} \mathrm{LiPF}_{6}{ }^{-} \mathrm{EC} / \mathrm{DMC}$ (v:v=1:1); (b) The calculated electrostatic potential of $\mathrm{LiPF}_{6}, \mathrm{PBI}$ unit and $\mathrm{PBI}$ unit/LiPF to illustrate the conjugated interaction between $\mathrm{Li}^{+}$and electron-rich imidazole ring; (c) The repulsive interaction between $\mathrm{PF}_{6}{ }^{-}$and electron-rich imidazole ring; (d) Schematic illustration of the electron-rich imidazole ring for promoting the $\mathrm{Li}^{+}$mobile and restricting $\mathrm{PF}_{6}{ }^{-}$mobile.

Conjugated interaction. The strong interaction between $\mathrm{Li}^{+}$and electron-rich imidazole ring to promote $\mathrm{Li}^{+}$diffusion are proved by X-ray photoelectron spectroscopy (XPS) and density functional theory (DFT) calculations. As depicted in Fig. 3a, two peaks are observed at around $398.7 \mathrm{eV}$ and $397.1 \mathrm{eV}$ for the neat PBI membrane, corresponding to the $-\mathrm{N}=\left(s p^{2}\right.$ hybrid $\mathrm{N}$ atom $)$ and $-\mathrm{NH}-\left(s p^{3}\right.$ hybrid $\mathrm{N}$ atom $)$ of the imidazole ring, respectively. However, one peak disappears after immersing the PBI membrane into $1.0 \mathrm{M} \mathrm{LiPF}_{6}$ in EC/DMC (v:v $\left.=1: 1\right)$ electrolyte and another peak shifts to $400.3 \mathrm{eV}$, indicating that the strong interaction forms between $\mathrm{LiPF}_{6}$ and PBI backbone.

As illustrated in Fig. 3b and Table S1, DFT calculations indicate that the highest occupied molecular orbital (HOMO) of the electron-rich imidazole ring in PBI can matches well with the lowest unoccupied molecular orbital (LUMO) of the $\mathrm{Li}^{+}$in $\mathrm{LiPF}_{6}$ to form N-Li conjugated bond with the bonding distance of $1.988 \AA$ and bonding energy of $-49.194 \mathrm{kcal} \mathrm{mol}^{-1}$. By contrast, the electron-rich imidazole ring shows repulsive interaction to $\mathrm{PF}_{6}^{-}$with long bonding distance of $3.415 \AA$ and bonding energy of $4.741 \mathrm{kcal} \mathrm{mol}^{-1}$ (Figs. $3 \mathrm{c}$ and S2). The formed conjugated bond contributes to the $\mathrm{Li}^{+}$dissociation from $\mathrm{PF}_{6}{ }^{-}$, serving as another $\mathrm{Li}^{+}$pathway in ep-PBIPE membrane while the movement of $\mathrm{PF}_{6}{ }^{-}$is restricted (Fig. 3d).

$\mathrm{Li}^{+}$transference number, Li stripping/plating performance and morphology of Li metal anode. The $\mathrm{Li}$ ion transference number of $e p$-PBIPE/LiPF ${ }_{6}$ was measured by a steady-state current method on the $\mathrm{Li}$ electrolyte $\mid \mathrm{Li}$ symmetric cell asseblied with the $e p-\mathrm{PBIPE} / \mathrm{LiPF}_{6}$ and $\mathrm{PP}-\mathrm{LiPF}_{6}{ }^{-} \mathrm{EC} / \mathrm{DMC}$ electrolyte at room temperature, the impedance spectra and the time-dependence response upon DC polarization are displayed in Fig. 4a. It shows that the $\mathrm{Li}$ ion transference number of ep-PBIPE/ $\mathrm{LiPF}_{6}$ electrolyte consequently increases from 0.23 (Fig. S3) for the Celgard/ $\mathrm{LiPF}_{6}$ electrolyte up to 0.76 , which is beneficial to improve the stability of Li stripping/plating, in particular, to suppress lithium dendrite growth ${ }^{36}$. The time-dependent interface stability between the ep-PBIPE/LiPF 6 electrolyte and Li metal based on impedance measurements of a Li $|e p-\mathrm{PBIPE} / \mathrm{LiPF}| \mathrm{Li}$ cell 

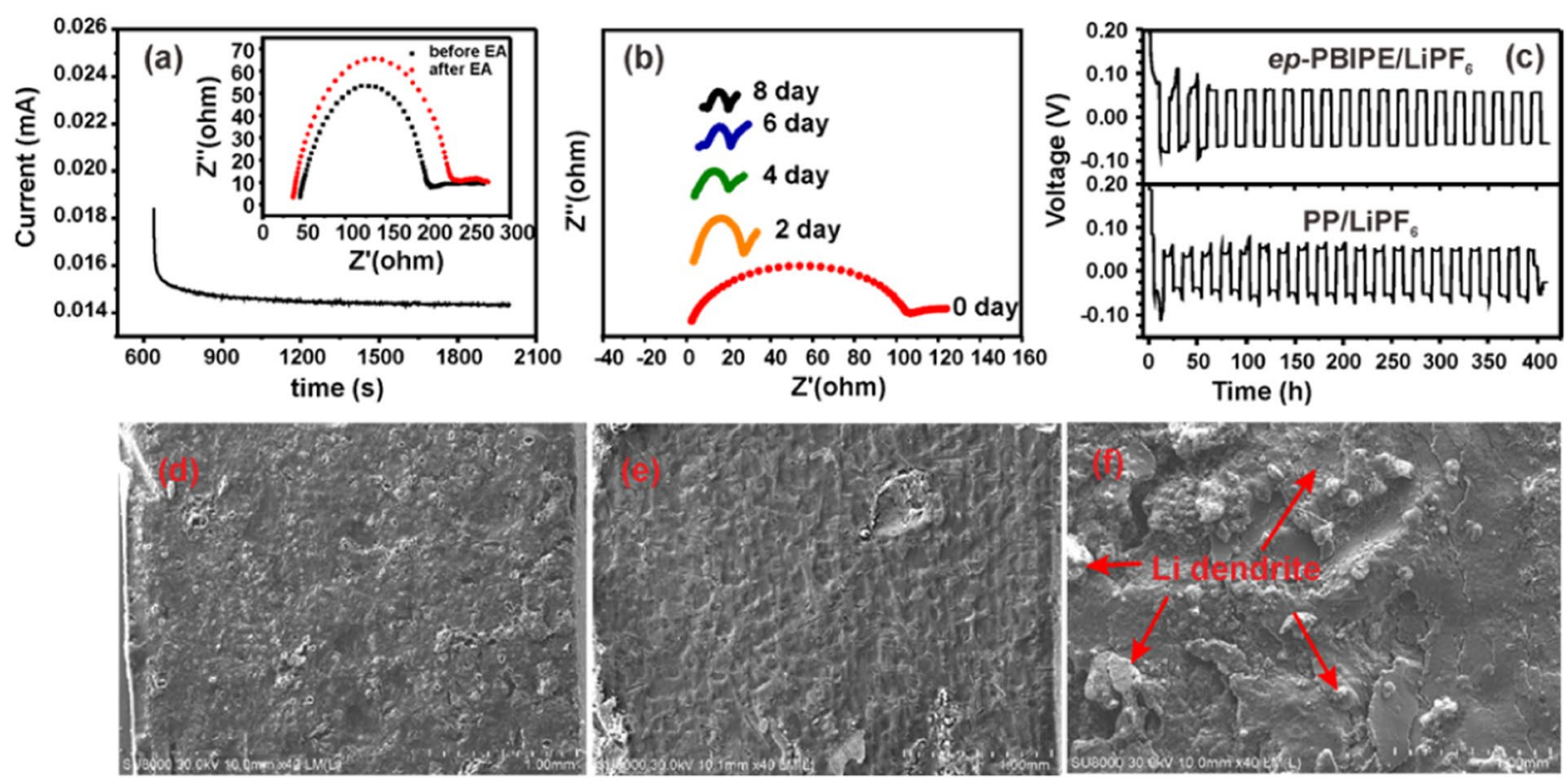

Figure 4. (a) The time-dependence response of dc polarization (inserted impedance spectra) for the ep-PBIPE/ $\mathrm{LiPF}_{6}{ }^{-} \mathrm{EC} / \mathrm{DMC}$ electrolyte on the $\mathrm{Li}\left|e p-\mathrm{PBIPE} / \mathrm{LiPF}_{6}\right| \mathrm{Li}$ symmetric cell, (b) Time evolution of the impedance response of a symmetrical $\mathrm{Li}\left|e p-\mathrm{PBIPE} / \mathrm{LiPF}_{6}\right| \mathrm{Li}$ cell (c) Galvanostatic cycling of symmetric lithium cells with the $e p-\mathrm{PBIPE} / \mathrm{LiPF}_{6}{ }^{-} \mathrm{EC} / \mathrm{DMC}$ electrolyte and the Celgard/ $/ \mathrm{LiPF}_{6}{ }^{-} \mathrm{EC} / \mathrm{DMC}$ electrolyte. SEM images of $\mathrm{Li}$ foil after long-term stripping/plating with $e p$-PBIPE/ $\mathrm{LiPF}_{6}{ }^{-} \mathrm{EC} / \mathrm{DMC}$ electrolyte (d), pristine Li foil (e) and Celgard/LiPF ${ }_{6}{ }^{-} \mathrm{EC} / \mathrm{DMC}$ electrolyte (f).

is depicted in Fig. 4b. It depicts that the resistance becomes constant after 4 day, demonstrating a stable interface between the Li and ep-PBIPE.

The stripping/plating performance of metallic lithium anodes was determined by the galvanostatic Li stripping/plating cycling test and the results are shown in Fig. 4c. Li/ $\mathrm{Li}$ symmetric cell at $0.5 \mathrm{~mA} \mathrm{~cm}^{-2}$ with the $e p$-PBIPE/LiPF ${ }_{6}$ electrolyte exhibits a stable voltage profile, which is consistant with the previously reported anion-anchoring single ion conducting polymer electrolytes ${ }^{37-39}$. In contrast, $\mathrm{Li} / \mathrm{Li}$ symmetric cell with the Celgard/ $\mathrm{LiPF}_{6}$ electrolyte shows fluctuating voltage profile with increasing voltage hysteresis, stemming from the depletion of cations at the Li/electrolyte interface ${ }^{40,41}$. Figure $4 \mathrm{~d}-\mathrm{f}$ shows the SEM images of Li foil with ep-PBIPE/ $\mathrm{LiPF}_{6}$ electrolyte and Celgard/LiPF 6 electrolyte after long cycles of stripping/plating. The top surface of Li electrode with $e p$-PBIPE/ $\mathrm{LiPF}_{6}$ electrolyte is relatively uniform (Fig. 4d), without an overgrowth of dendrites, which is similar with the neat $\mathrm{Li}$ foil (Fig. $4 \mathrm{e}$ ). In contrast, the Li foil in Celgard/LiPF 6 electrolyte exhibits a mossy, dendritic deposition (Fig. 4f).

Thermal stability and fire- retardancy. It is known that good thermal stabilities, including high thermal decomposition temperature and good dimensional stability are key parameters for battery separators, playing a vital role in preventing the thermal runaway when commercial batteries overheat caused by overcharge, overdischarge, internal and external short circuit or accidents ${ }^{42-44}$. Thermo-gravimetric (TG) analysis is employed to investigate the thermal stability of the Celgard separator and ep-PBIPE. As shown in Fig. 5a, the thermal decomposition temperatures reach up to $400^{\circ} \mathrm{C}$ and $550^{\circ} \mathrm{C}$, respectively, for the Celgard separator and $e p$-PBIPE, which are much higher than the required temperature of $80^{\circ} \mathrm{C}$. However, differential scanning calorimeter (DSC) analysis in Fig. $5 \mathrm{~b}$ reveals that the Celgard separator possesses soften point and melting point at $132^{\circ} \mathrm{C}$ and $157^{\circ} \mathrm{C}$, respectively, representing the poor thermal dimensional stability (Fig. $5 \mathrm{c}$ ). In contrast, no endothermic peak is observed for the ep-PBIPE even at high temperature of $350^{\circ} \mathrm{C}$, which is consistent with the high thermal dimensional stability without any shrinkage at $300^{\circ} \mathrm{C}$. Moreover, the fire-retardancy tests indicate that the $e p$-PBIPE is nonflammable and exhibit intriguing fire-retarding properties, benefiting from the intrinsic flame-retardancy of PBI (Fig. 5d-g).

Wettability. Figure $6 \mathrm{a}-\mathrm{f}$ shows the electrolyte wettability of the Celgard separator and $e p$-PBIPE determined by the contact angle measurements. The Celgard separator displays a slow electrolyte wetting with high contact angle of $51^{\circ}$ after $90 \mathrm{~s}$ (Fig. $6 \mathrm{a}-\mathrm{c}$ ). The poor electrolyte wetting is caused by the nonpolar nature of the polyolefin polymer, originated from an intrinsically hydrophobic property and low surface energy ${ }^{45,46}$. In contrast, the electrolyte completely penetrates into the ep-PBIPE within $10 \mathrm{~s}$ (Fig. $6 \mathrm{~d}-\mathrm{f}$ ). Besides the rather different pore structures, the fast electrolyte wetting of the ep-PBIPE is attributed to its highly polar imidazole ring. Accordingly, the superior electrolyte wetting leads to good electrolyte interfacial contact and small interfacial resistance ${ }^{26,47}$.

Electrochemical performance. The high ionic conductivity and good electrode compatibility of polymer electrolytes are crucial for the power density of LIBs. The temperature dependence of ionic conductivity of 

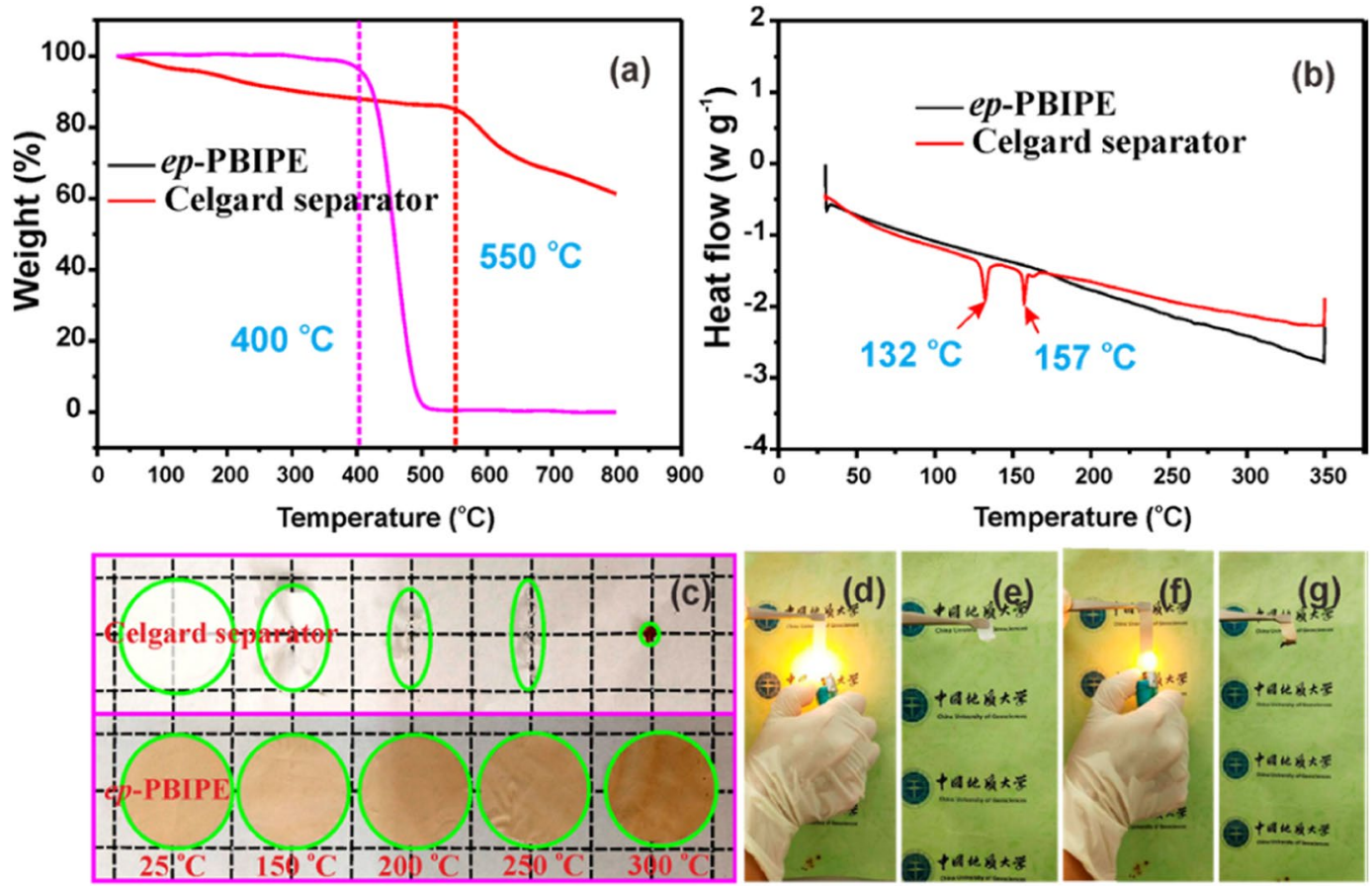

Figure 5. (a) TG curves and (b) DSC curves of Celgard and ep-PBIPE membranes, (c) Thermal shrinkage images of Celgard separator and $e p$-PBIPE membrane. Fire-resistance test of Celgard, before (d) and after (e) burning, and ep-PBIPE membrane, before (f) and after (g) burning.
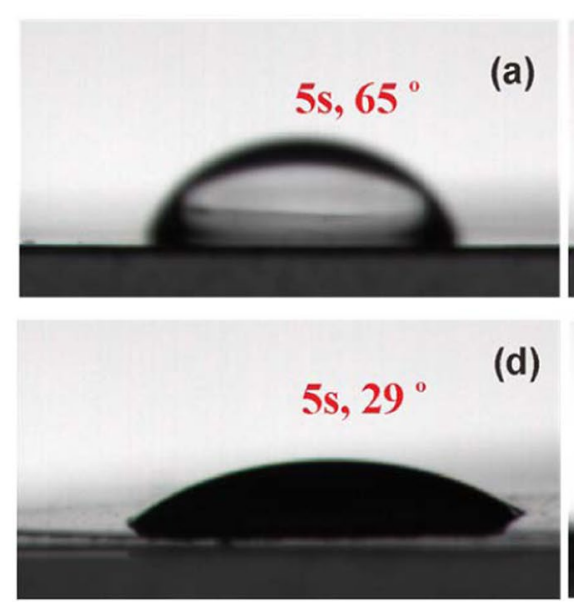

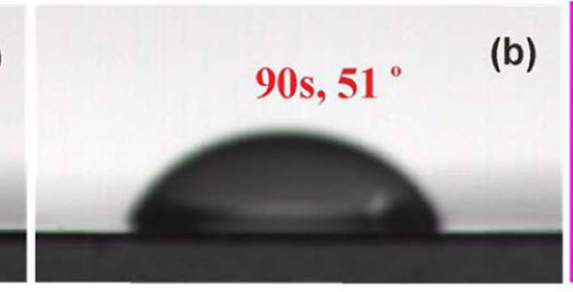

(b)

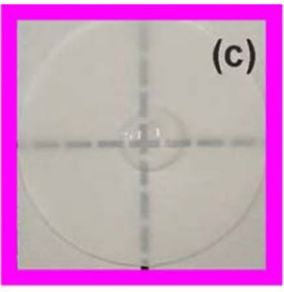

(e)

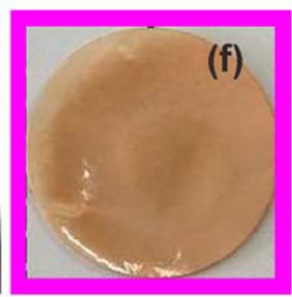

Figure 6. Contact angles of $1.0 \mathrm{M} \mathrm{LiPF}_{6}$ in EC/DMC liquid electrolyte on Celgard separator after (a) $5 \mathrm{~s}$, (b) $90 \mathrm{~s}$, and (c) the photo after $60 \mathrm{~s}$, and contact angles of $1.0 \mathrm{M} \mathrm{LiPF}_{6}$ in EC/DMC electrolyte on ep-PBIPE membrane after (d) $5 \mathrm{~s}$, (e) $10 \mathrm{~s}$, and (f) the image after $60 \mathrm{~s}$ wetting.

the ep-PBIPE membrane and Celgard separator, soaking with $1.0 \mathrm{M} \mathrm{LiPF}_{6}{ }^{-} \mathrm{EC} / \mathrm{DMC}$, is depicted in Fig. 7a. The ionic conductivity of the ep-PBIPE/1.0 M LiPF${ }_{6}{ }^{-} \mathrm{EC} / \mathrm{DMC}$ is $1.16 \mathrm{mS} \mathrm{cm}{ }^{-1}$, which is much higher than that of Celgard/1.0 $\mathrm{M} \mathrm{LiPF}_{6}{ }^{-} \mathrm{EC} / \mathrm{DMC}\left(0.44 \mathrm{mS} \mathrm{cm}^{-1}\right)$. Figure $7 \mathrm{~b}$ shows the Nyquist plots of symmetric cells with two electrolytes. Favored by high porosity to absorb more electrolytes, the assembled cell with ep-PBIPE membrane exhibits reduced interfacial resistance.

The electrochemical performances with the ep-PBIPE/1.0 $\mathrm{M} \mathrm{LiPF}_{6}{ }^{-} \mathrm{EC} / \mathrm{DMC}$ and Celgard/1.0 $\mathrm{M} \mathrm{LiPF}_{6}-\mathrm{EC} /$ DMC electrolytes are evaluated in $\mathrm{Li} / \mathrm{LiFePO}_{4}$ cells. As depicted in Fig. 7c, $\mathrm{Li} / \mathrm{LiFePO}_{4}$ cell with the ep-PBIPE membrane demonstrates reversible discharge capacity of $151 \mathrm{mAh} \mathrm{g}^{-1}$ at $0.1 \mathrm{C}$, close to the theoretical capacity $\left(\mathrm{LiFePO}_{4}, 170 \mathrm{mAh} \mathrm{g}^{-1}\right)$. Even at high current density of 6C, it still maintains high discharge capacity of $>100 \mathrm{mAh} \mathrm{g}^{-1}$ (Fig. 7d), which is much higher than that of $87 \mathrm{mAh} \mathrm{g}^{-1}$ for the cell with Celgard separator. The cycling performances with two electrolytes at $6 \mathrm{C}$ are shown in Fig. 7e. The $\mathrm{Li} / \mathrm{LiFePO}_{4}$ cell with the ep-PBIPE-based electrolyte delivers an initial discharge capacity of $101 \mathrm{mAh} \mathrm{g}^{-1}$, higher than that of $83 \mathrm{mAh}$ $\mathrm{g}^{-1}$ for the Celgard-based electrolyte, and the capacity retention is $92.1 \%$ after 1000 cycles, corresponding to a 

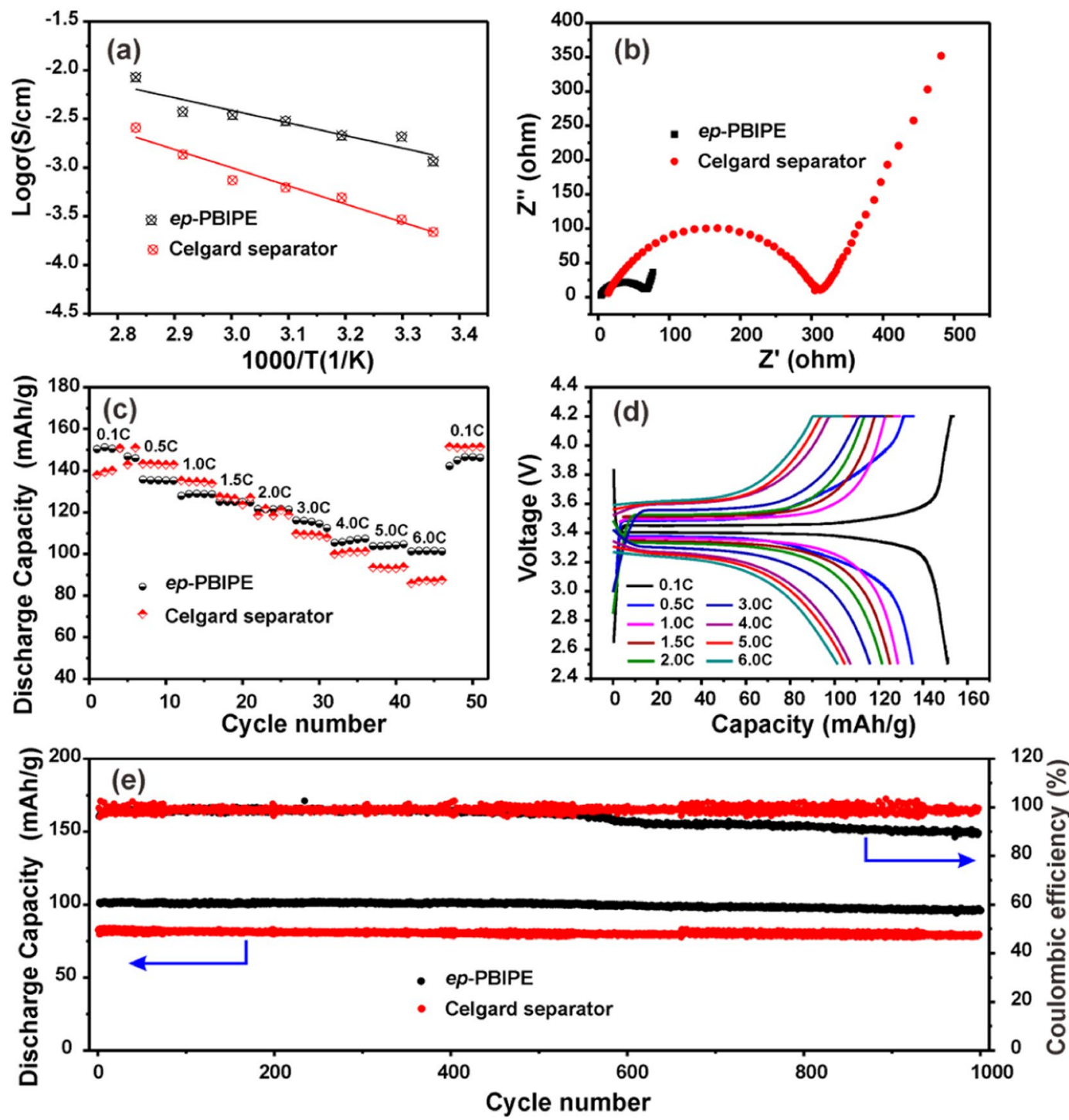

Figure 7. Comparison of electrochemical performances of ep-PBIPE and Celgard separator with 1.0 M LiPF in EC/DMC electrolyte. (a) Ionic conductivities; (b) Interfacial resistances; (c) Rate performances of $\mathrm{Li} / \mathrm{LiFePO}_{4}$ cells; (d) Discharge/charge profiles at selected C-rates; (e) Long-term cycle performance at 6 C.

capacity loss of $0.0079 \%$ per cycle, which is attributed to excellent electrochemical stability (Fig. S4). Furthermore, we found that the coulombic efficiency of ep-PBIPE-based separator is much lower than that of Celgard separator after $\sim 600$ cycles. As we know that when the coulombic efficiency reaches below $95 \%$, it suggests the failure of the lithium metal battery. Therefore, the stable cycling might be achieved by overwhelm usage of lithium metal rather than the merits of the separator. These results suggest that the ep-PBIPE membrane exhibits high potential application in high-density and safe Li metal batteries.

In conclusion, a series of PBI-based polymer electrolytes ( $p$-PBIPEs) were successfully fabricated via a facile non-solvent induced phase separation process. The results indicate that ethanol is the best coagulation bath for highly porous $p$-PBIPE ( $e p$-PBIPE) membrane with well-interconnected sponge-like pore structure and appropriate mechanical strength. In particular, the strong conjugated interaction between $\mathrm{Li}^{+}$and electron-rich imidazole ring is greatly favorable for improving the $\mathrm{Li}^{+}$dissociation and migration, subsequently increasing $\mathrm{Li}^{+}$transference number up to 0.76 , and can effectively suppress the lithium dendrites growth. This enables stable Li stripping/plating for more than $400 \mathrm{~h}$. In addition, the highly rigid and fully aromatic PBI backbone results in high thermal stability of $e p$-PBIPE membrane even at $300^{\circ} \mathrm{C}$, and the high polarity of imidazole ring and high porosity guarantees fast electrolyte wetting within $10 \mathrm{~s}$. The $\mathrm{Li} / \mathrm{LiFePO}_{4}$ battery with the $e p$-PBIPE membrane exhibits excellent rate performance of $>100 \mathrm{mAh} \mathrm{g}^{-1}$ at $6 \mathrm{C}$ and outstanding electrochemical stability for 1000 cycles.

\section{Experimental Section}

Materials. Polybenzimidazoles (PBI) was purchased from Suzhou Pinyu Optoelectronics Technology Co., Ltd. Lithium iron phosphate (LiFePO4), PVDF, and conductive agent (Acetylene Black) were purchased from Shanghai Darui Fine Chemical Co., Ltd., and used as received. N,Ndimethylacetamide (DMAC, AR, Aladdin) 


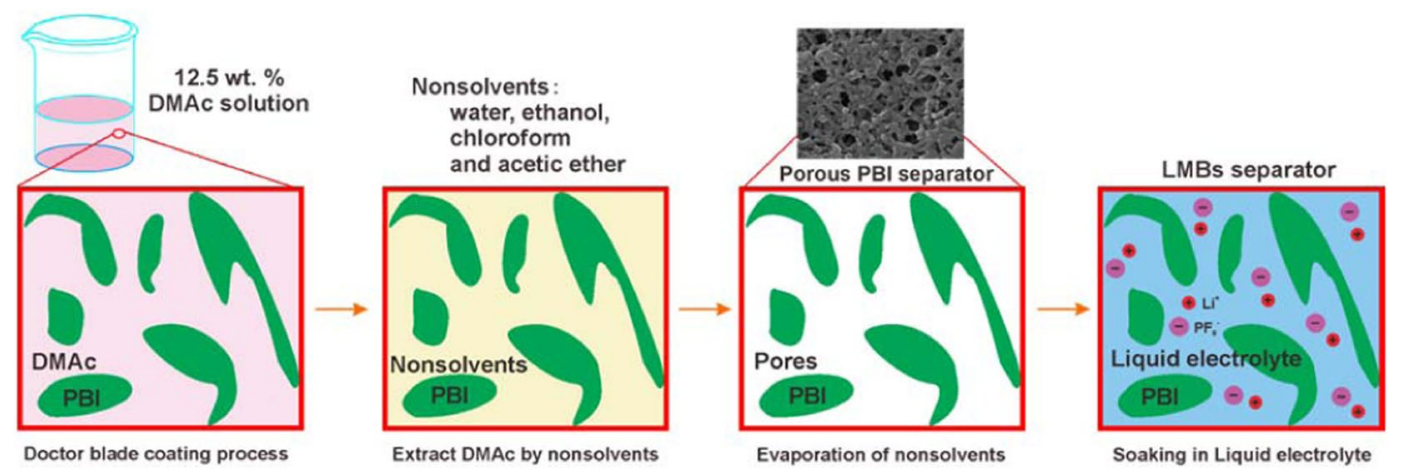

Figure 8. The illustration of the NIPS process for preparation of the porous PBI separator.

and N-Methyl-2-pyrrolidone (NMP, Anhydrous grade, 99.5\%, Aladdin) were used as received. PP membrane (Celgard 2400) was cut into $19 \mathrm{~mm}$ film for use.

Fabrication of p-PBIPE membranes. The non-solvent induced phase separation process was conducted according to our previous publication ${ }^{45}$. To investigate the effect of different coagulation bath solvents on the properties of the membranes, the four solvents with different polarity, water, ethanol, ethyl acetate and chloroform, were selected as solvents. As illustrated in Fig. 8, the calculated amount of PBI was first dissolved in $\mathrm{N}, \mathrm{N}$-dimethylacetamide (DMAc) to prepare a $12.5 \mathrm{wt} \%$ uniform casting solution. Afterward, the homogenous solution was cast onto a clean glass plate to prepare a film with average thickness of $35 \mu \mathrm{m}$. The film was quickly immersed in the mentioned four coagulation baths for $0.5 \mathrm{~h}$ to exchange DMAc solvent. Finally, the formed $p$-PBIPEs were dried at room temperature for $12 \mathrm{~h}$ followed by at $100^{\circ} \mathrm{C}$ for $24 \mathrm{~h}$ in a vacuum oven.

Preparation of $\mathrm{LiFePO}_{4}$ electrode and battery assembly. The $\mathrm{LiFePO}_{4}$ cathode consisting of a mixture of $\mathrm{LiFePO}_{4}$ active material, acetylene black (AB) and binder of PVDF at a mass ratio of 7:2:1 was prepared by the following steps. PVDF binder was firstly dissolved in NMP, and the well-mixed mixture was then added into the above solution and stirred for at least $4 \mathrm{~h}$ to form homogeneous slurry. After that, the slurry was cast on an aluminum foil, dried at $60^{\circ} \mathrm{C}$ for $12 \mathrm{~h}$, and cut into $15 \mathrm{~mm}$ discs for use as the cathode of a coin cell and the mass loading of the cathode is approximately $4 \mathrm{mg} \mathrm{cm}^{-2}$. Finally, the as-prepared cathode film was completely dried at $80^{\circ} \mathrm{C}$ in a vacuum oven overnight and then transferred into an argon-filled glove box for further characterization. The $\mathrm{Li} / \mathrm{LiFePO}_{4}$ half-cells were assembled with $p$-PBIPE membrane and Celgard as separators and $1.0 \mathrm{M}$ $\mathrm{LiPF}_{6}{ }^{-} \mathrm{EC} / \mathrm{DMC}(\mathrm{v} / \mathrm{v}=1: 1)$ as electrolyte.

Characterization. The morphology of the membranes was studied using a scanning electron microscope (FE-SEM, SU8010, HITACHI). Samples must be sprayed with gold for $100 \mathrm{~s}$ before testing. The interaction between $p$-PBIPEs membrane and $\mathrm{LiFP}_{6}$ was analyzed by the X-ray photoelectron spectroscopy (XPS, Escalab 250xi, Thermo Fisher) and the testing samples were the $p$-PBIPEs membranes before and after immersed in $1 \mathrm{M}$ $\mathrm{LiPF}_{6} / \mathrm{EC} / \mathrm{DMC}(\mathrm{v}: \mathrm{v}=1: 1)$. The tensile strength and elongation tests of membranes were indicated using a tensile tester XLW (PC) at a strain rate of $25 \mathrm{~mm} / \mathrm{min}$. The thermal stability of membranes was characterized thermogravimetric analyzer (STA $449 \mathrm{~F} 3$, Germany NETZSCH) under an atmosphere of nitrogen with temperature range of from 30 to $800^{\circ} \mathrm{C}$ at a rate of $10^{\circ} \mathrm{C} \mathrm{min}{ }^{-1}$. The endothermic and exothermic behaviors were investigated using Differential Scanning Calorimetry (METTLER TOLEDO DSC3) under nitrogen flow from 30 to $350^{\circ} \mathrm{C}$. The wettability of membranes with electrolyte was conducted by static contact angle and electrolyte spreading test. The thermal shrinkage test was performed by putting the membranes in a heating plate at various temperatures $\left(150,200,250\right.$ and $\left.300^{\circ} \mathrm{C}\right)$, for $0.5 \mathrm{~h}$ at each temperature. The electrochemical stability was measured by the cyclic voltammetry $(\mathrm{CV})$ with the membrane was sandwiched by a lithium electrode and a stainless steel (SS) electrode. The voltage was swept at the scan rate of $0.5 \mathrm{mV} \mathrm{s}^{-1}$ from $-1.0 \mathrm{~V}$ to $5.0 \mathrm{~V}\left(\mathrm{vs}\right.$. $\left.\mathrm{Li} / \mathrm{Li}^{+}\right)$.

The electrolyte uptake of the membrane was measured by immersing the membrane in a liquid electrolyte $\left(1 \mathrm{M} \mathrm{LiPF}_{6}\right.$ in EC / DMC, $\left.1: 1 \mathrm{v} / \mathrm{v}\right)$ for $24 \mathrm{~h}$ for achieving complete soakage. The weights of dry membrane $\left(\mathrm{M}_{0}\right)$ and wet membrane $\left(M_{1}\right)$ were obtained by accurately weighing the mass before and after the membrane soakage. The electrolyte uptake was calculated by the following Eq. (1):

$$
\text { Solvent uptake }=\frac{M_{1}+M_{0}}{M_{0}} \times 100 \%
$$

The process for determination of porosity $(\mathrm{P})$ of the membrane is as follows. The dry membrane was immersed in $\mathrm{n}$-butanol for $24 \mathrm{~h}$ for soaking the solvent in pore. The weight of the dry membrane and wet membrane were measured, respectively, and then the porosity was calculated according to the following Eq. (2):

$$
P \%=\frac{W_{w}-W_{d}}{\rho b * V_{m}} \times 100 \%
$$


where $W_{d}$ is the dry weight of membrane, $W_{w}$ is the wet weight of membrane, $\rho_{b}$ is the density of $n$-butanol and $\mathrm{V}_{\mathrm{m}}$ is the volume of the membrane.

The ionic conductivity $(\sigma)$ of polymer electrolytes was tested using electrochemical impedance spectroscopy (EIS) by sandwiching the electrolyte-soaked membrane between two stainless steel (SS) electrodes. The impedance data was recorded over a frequency range from $10^{6} \mathrm{~Hz}$ to $1 \mathrm{~Hz}$ and the oscillating voltage of $5 \mathrm{mV}$. The ionic conductivity $(\sigma)$ was calculated by the following Eq. (3):

$$
\sigma=\frac{l}{R A}
$$

where $\mathrm{l}$ and $\mathrm{A}$ are the thickness and effective area of a membrane, respectively. And R is the impedance $(\Omega)$ of the membrane measured by EIS.

The lithium ion transference number $\left(\mathrm{t}^{+}\right)$was measured by sandwiching the membrane between two lithium electrodes. The lithium ion transference number $\left(\mathrm{t}^{+}\right)$was calculated by the following Eq. (4):

$$
t^{+}=\frac{I_{s}\left(\Delta V-I_{0} R_{0}\right)}{I_{0}\left(\Delta V-I_{s} R_{s}\right)}
$$

where $\Delta \mathrm{V}$ is the set polarization voltage, $\mathrm{I}_{0}$ and $\mathrm{I}_{\mathrm{S}}$ are the initial and steady-state currents, and $\mathrm{R}_{0}$ and $\mathrm{R}_{\mathrm{S}}$ are the initial and steady-state resistances of the passivating layers on the Li electrode.

Received: 15 August 2019; Accepted: 23 November 2019;

Published online: 17 December 2019

\section{References}

1. Li, M., Lu, J., Chen, Z. \& Amine, K. 30 Years of Lithium-Ion Batteries. Adv Mater, e1800561 (2018).

2. Li, C. et al. Single-Ion Conducting Electrolyte Based on Electrospun Nanofibers for High-Performance Lithium Batteries Advanced Energy. Materials 9, 1970029 (2019).

3. Zhu, M. et al. A Biobased Composite Gel Polymer Electrolyte with Functions of Lithium Dendrites Suppressing and Manganese Ions Trapping. Advanced Energy. Materials 8, 1702561 (2018).

4. Duan, H. et al. Dendrite-Free Li-Metal Battery Enabled by a Thin Asymmetric Solid Electrolyte with Engineered Layers. J Am Chem Soc 140, 82-85 (2018).

5. Deng, K. et al. Effective Suppression of Lithium Dendrite Growth Using a Flexible Single-Ion Conducting Polymer Electrolyte. Small, e1801420 (2018).

6. Khan, M. A. et al. Recent Progresses in Electrocatalysts for Water Electrolysis. Electrochemical Energy Reviews 1, 483-530 (2018).

7. Porcarelli, L. et al. Single-Ion Conducting Polymer Electrolytes for Lithium Metal Polymer Batteries that Operate at Ambient Temperature. ACS Energy Letters 1, 678-682 (2016).

8. Zhang, Y. et al. A gel single ion polymer electrolyte membrane for lithium-ion batteries with wide-temperature range operability. RSC Adv. 4, 21163-21170 (2014).

9. Xu, R. et al. Dual-Phase Single-Ion Pathway Interfaces for Robust Lithium Metal in Working Batteries. Advanced Materials 31, 1808392 (2019)

10. Zhao, C.-Z. et al. An anion-immobilized composite electrolyte for dendrite-free lithium metal anodes. Proceedings of the National Academy of Sciences 114, 11069-11074 (2017).

11. Tu, Z. et al. Designing Artificial Solid-Electrolyte Interphases for Single-Ion and High-Efficiency Transport in. Batteries. Joule 1, 394-406 (2017).

12. Zhao, C.-Z. et al. An ion redistributor for dendrite-free lithium metal anodes. Science Advances 4, eaat3446 (2018).

13. Liang, X., Yang, Y., Jin, X., Huang, Z. \& Kang, F. The high performances of $\mathrm{SiO} 2 / \mathrm{Al} 2 \mathrm{O} 3$-coated electrospun polyimide fibrous separator for lithium-ion battery. Journal of Membrane Science 493, 1-7 (2015).

14. Shi, C. et al. A high-temperature stable ceramic-coated separator prepared with polyimide binder/ $\mathrm{Al} 2 \mathrm{O} 3$ particles for lithium-ion batteries. Journal of Membrane Science 517, 91-99 (2016).

15. Wang, Y., Wang, S., Fang, J., Ding, L.-X. \& Wang, H. A nano-silica modified polyimide nanofiber separator with enhanced thermal and wetting properties for high safety lithium-ion batteries. Journal of Membrane Science 537, 248-254 (2017).

16. Lin, Z., Guo, X. \& Yu, H. Amorphous modified silyl-terminated 3D polymer electrolyte for high-performance lithium metal battery. Nano Energy 41, 646-653 (2017).

17. Chen, G., Zhang, F., Zhou, Z., Li, J. \& Tang, Y. A Flexible Dual-Ion Battery Based on PVDF-HFP-Modified Gel Polymer Electrolyte with Excellent Cycling Performance and Superior Rate Capability. Advanced Energy. Materials 8, 1801219 (2018).

18. Zhang, Y. et al. Highly porous single-ion conductive composite polymer electrolyte for high performance Li-ion batteries. Journal of Power Sources 397, 79-86 (2018).

19. Li, D. et al. A low cost shutdown sandwich-like composite membrane with superior thermo-stability for lithium-ion battery. Journal of Membrane Science 542, 1-7 (2017).

20. Liu, Y. et al. A mechanically robust porous single ion conducting electrolyte membrane fabricated via self-assembly. Journal of Membrane Science 507, 99-106 (2016).

21. Love, C. T. Thermomechanical analysis and durability of commercial micro-porous polymer Li-ion battery separators. Journal of Power Sources 196, 2905-2912 (2011).

22. Woods, J., Bhattarai, N., Chapagain, P., Yang, Y. \& Neupane, S. In situ transmission electron microscopy observations of rechargeable lithium ion batteries. Nano Energy 56, 619-640 (2019).

23. Zhang, Y. et al. Lithium-Ion Batteries with a Wide Temperature Range Operability Enabled by Highly Conductive sp3Boron-Based Single Ion Polymer Electrolytes. Energy Technology 2, 643-650 (2014).

24. Zhang, Y. et al. Design and synthesis of a single ion conducting block copolymer electrolyte with multifunctionality for lithium ion batteries. RSC Adv. 4, 43857-43864 (2014).

25. Lv, P. et al. Robust Succinonitrile-Based Gel Polymer Electrolyte for Lithium-Ion Batteries Withstanding Mechanical Folding and High Temperature. ACS Appl Mater Interfaces 10, 25384-25392 (2018).

26. Li, D. et al. Superior Thermally Stable and Nonflammable Porous Polybenzimidazole Membrane with High Wettability for HighPower Lithium-Ion Batteries. ACS Applied Materials \& Interfaces 9, 8742-8750 (2017).

27. Liang, N., Fang, J. \& Guo, X. A simple approach for preparation of porous polybenzimidazole membranes as a promising separator for lithium ion batteries. Journal of Materials Chemistry A 5, 15087-15095 (2017). 
28. Zhang, Y. et al. Influence of chemical microstructure of single-ion polymeric electrolyte membranes on performance of lithium-ion batteries. ACS Appl Mater Interfaces 6, 17534-42 (2014).

29. Jana, A. \& García, R. E. Lithium dendrite growth mechanisms in liquid electrolytes. Nano Energy 41, 552-565 (2017).

30. Gerbaldi, C. et al. Innovative high performing metal organic framework (MOF)-laden nanocomposite polymer electrolytes for allsolid-state lithium batteries. Journal of Materials Chemistry A 2, 9948-9954 (2014).

31. Zhang, Y. et al. Toward ambient temperature operation with all-solid-state lithium metal batteries with a sp 3 boron-based solid single ion conducting polymer electrolyte. Journal of Power Sources 306, 152-161 (2016).

32. Chen, Y. et al. A dual-layer micro/nanostructured fibrous membrane with enhanced ionic conductivity for lithium-ion battery. Electrochimica Acta 292, 357-363 (2018).

33. Zhai, Y., Xiao, K., Yu, J., Yang, J. \& Ding, B. Thermostable and nonflammable silica-polyetherimide-polyurethane nanofibrous separators for high power lithium ion batteries. Journal of Materials Chemistry A 3, 10551-10558 (2015).

34. Xue, Z. M., Ding, J., Zhou, W. \& Chen, C. H. Density functional theory study on LBDOB and its derivatives: Electronic structures, energies, and molecular properties. Electrochimica Acta 55, 3838-3844 (2010).

35. Lever, A. B. P. Electronic characteristics of an extensive series of ruthenium complexes with the non-innocent o-benzoquinonediimine ligand: A pedagogical approach. Coordination Chemistry Reviews 254, 1397-1405 (2010).

36. Miao, R. et al. A new ether-based electrolyte for dendrite-free lithium-metal based rechargeable batteries. Sci Rep 6, 21771 (2016).

37. Xu, D. et al. High-Strength Internal Cross-Linking Bacterial Cellulose-Network-Based Gel Polymer Electrolyte for DendriteSuppressing and High-Rate Lithium Batteries. ACS Appl Mater Interfaces 10, 17809-17819 (2018).

38. Zahn, R., Lagadec, M. F., Hess, M. \& Wood, V. Improving Ionic Conductivity and Lithium-Ion Transference Number in Lithium-Ion Battery Separators. ACS Applied Materials \& Interfaces 8, 32637-32642 (2016).

39. Zhang, Y. et al. A class of sp3 boron-based single-ion polymeric electrolytes for lithium ion batteries. RSC Advances 3, 14934 (2013).

40. Wan, G. et al. Suppression of Dendritic Lithium Growth by in Situ Formation of a Chemically Stable and Mechanically Strong Solid Electrolyte Interphase. ACS Appl Mater Interfaces 10, 593-601 (2018).

41. Zhang, H. et al. Recent progress in advanced electrode materials, separators and electrolytes for lithium batteries. Journal of Materials Chemistry A 6, 20564-20620 (2018).

42. Li, D., Shi, D., Feng, K., Li, X. \& Zhang, H. Poly (ether ether ketone) (PEEK) porous membranes with super high thermal stability and high rate capability for lithium-ion batteries. Journal of Membrane Science 530, 125-131 (2017).

43. Shi, C. et al. Functional separator consisted of polyimide nonwoven fabrics and polyethylene coating layer for lithium-ion batteries. Journal of Power Sources 298, 158-165 (2015).

44. Shayapat, J., Chung, O. H. \& Park, J. S. Electrospun polyimide-composite separator for lithium-ion batteries. Electrochimica Acta 170, 110-121 (2015).

45. Dong, J. et al. Highly porous single ion conducting polymer electrolyte for advanced lithium-ion batteries via facile water-induced phase separation process. Journal of Membrane Science 568, 22-29 (2018).

46. Li, D., Zhang, H. \& Li, X. Porous polyetherimide membranes with tunable morphology for lithium-ion battery. Journal of Membrane Science 565, 42-49 (2018).

47. Ma, Q. et al. Single Lithium-Ion Conducting Polymer Electrolytes Based on a Super-Delocalized Polyanion. Angew Chem Int Ed Engl 55, 2521-5 (2016).

\section{Acknowledgements}

The authors gratefully acknowledge support of the National Natural Science Foundation of China (Nos 21603197 and 51872127), National Key R\&D Program of China (2018YFB15029), Natural Science Foundation of Hubei Province (No. 2016CFB181), Fundamental Research Funds for the Central University, China University of Geosciences, Wuhan (No. CUGL180403) and China University of Geosciences (Wuhan) for the program of Center for Advanced Energy Research and Technologies.

\section{Author contributions}

J.W., Y.Z., D.Z. and H.C. conceived and designed this work; J.W. performed the experiments; Y.H., Q.W., Z.L., Z.L., S.H. and J.D. provided some help with experimental testing. J.W. and Y.Z. prepared this manuscript; all authors read and fnalized the fnal manuscript.

\section{Competing interests}

The authors declare no competing interests.

\section{Additional information}

Supplementary information is available for this paper at https://doi.org/10.1038/s41598-019-55865-6.

Correspondence and requests for materials should be addressed to Y.Z.

Reprints and permissions information is available at www.nature.com/reprints.

Publisher's note Springer Nature remains neutral with regard to jurisdictional claims in published maps and institutional affiliations.

Open Access This article is licensed under a Creative Commons Attribution 4.0 International License, which permits use, sharing, adaptation, distribution and reproduction in any medium or format, as long as you give appropriate credit to the original author(s) and the source, provide a link to the Creative Commons license, and indicate if changes were made. The images or other third party material in this article are included in the article's Creative Commons license, unless indicated otherwise in a credit line to the material. If material is not included in the article's Creative Commons license and your intended use is not permitted by statutory regulation or exceeds the permitted use, you will need to obtain permission directly from the copyright holder. To view a copy of this license, visit http://creativecommons.org/licenses/by/4.0/.

(C) The Author(s) 2019 